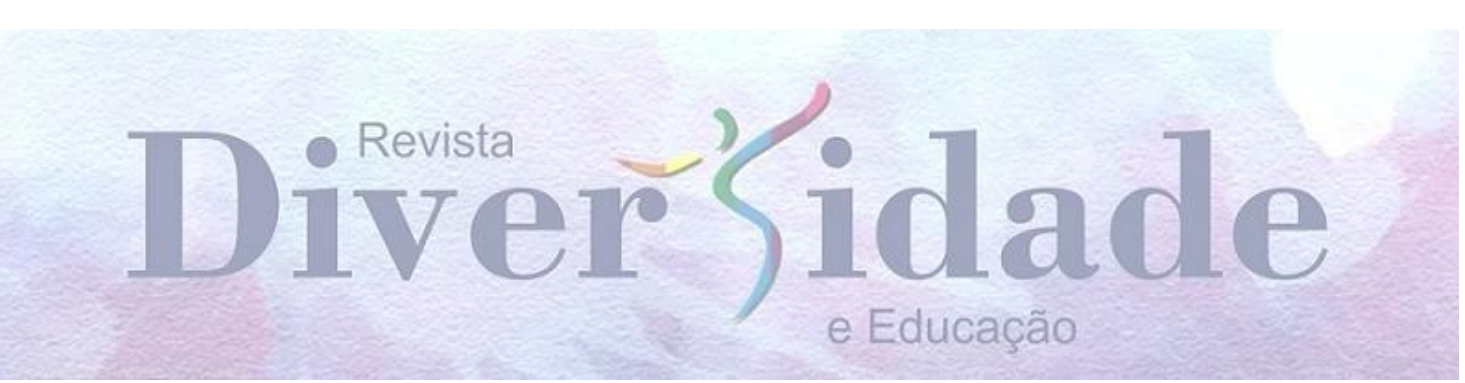

\title{
ESCOLA, GÊNERO E ABJEÇÃO: DESDOBRAMENTOS A PARTIR DA ALEGORIA NA ANIMAÇÃO X-MEN: EVOLUTION
}

\section{ESCUELA, GÉNERO Y ABJECCIÓN: DESARROLLOS DE LA ALEGORÍA EN ANIMACIÓN X-MEN: EVOLUCIÓN}

\section{SCHOOL, GENDER AND ABJECTION: DEVELOPMENTS FROM THE ALLEGORY IN ANIMATION X-MEN: EVOLUTION}

\author{
Marco Aurélio de Carvalhor \\ Paulo Rennes Marçal Ribeiro2
}

\section{RESUMO}

Super-heróis ao longo dos anos se consagraram como entretenimento de crianças, jovens e adultos, sendo, muitas vezes, taxados preconceituosamente de cultura inútil. No entanto, alguns educadores têm defendido o seu uso no processo de aprendizagem. No que diz respeito à sexualidade, em especial a aquelas dissidentes da cisheteronormatividade, há poucos heróis que tratam esse assunto de forma explícita. Tal abordagem muitas vezes se dá sob a forma de alegorias. É o caso dos $X$-men que foram concebidos por Stan Lee como uma alegoria de minorias sociais da vida real. Esse artigo tem como proposta discutir, a partir do conceito de abjeção, como os mutantes são uma alegoria da vivência de alunos LGBTQI+ na escola através da série animada $X$-men: Evolution. Acreditamos que os $X$-men possam vir a ser um instrumento importante para educadores trabalharem a questão da homofobia e transfobia em sala de aula.

PALAVRAS-CHAVE: $X$-men; Gênero; Abjeção; Escola.

\section{RESUMEN}

Los superhéroes a lo largo de los años se han consagrado como entretenimiento para niños, jóvenes y adultos, a menudo con prejuicios contra la cultura inútil. Sin embargo, algunos educadores han abogado por su uso en el proceso de aprendizaje. Con respecto a la sexualidad, especialmente aquellos que disienten de la cisheteronormatividad, hay pocos héroes que aborden este tema explícitamente. Tal enfoque a menudo toma la

1 Mestrando em Educação Sexual na Universidade Estadual Paulista "Júlio de Mesquita Filho" - UNESP, em Araraquara. E-mail: marco_carvalho@outlook.com.br

${ }_{2}$ Professor Associado no Departamento de Psicologia da Educação. Universidade Estadual Paulista "Júlio de Mesquita Filho" - UNESP, em Araraquara. Coordenador do Mestrado em Educação Sexual. E-mail: paulo.rennes@unesp.br 
forma de alegorías. Este es el caso de los X-men que fueron concebidos por Stan Lee como una alegoría de las minorías sociales de la vida real. Este artículo tiene como objetivo discutir, basado en el concepto de abyección, cómo los mutantes son una alegoría de la experiencia de los estudiantes LGBTQI + en la escuela a través de la serie animada X-men: Evolution. Creemos que los X-men pueden convertirse en una herramienta importante para que los educadores trabajen en la homofobia y la transfobia en el aula.

PALABRAS-CLAVE: $X$-men; Género; Abyección; Escuela.

\section{ABSTRACT}

Superheroes over the years have consecrated themselves as entertainment for children, young people and adults, often being prejudiced against useless culture. However, some educators have advocated its use in the learning process. With regard to sexuality, especially those dissenting from cisheteronormativity, there are few heroes who address this issue explicitly. Such an approach often takes the form of allegories. This is the case of the $X$-men that were conceived by Stan Lee as an allegory of real-life social minorities. This article aims to discuss, based on the concept of abjection, how mutants are an allegory of the experience of LGBTQI + students at school through the animated series $X$-men: Evolution. We believe that $X$-men can become an important tool for educators to work on homophobia and transphobia in the classroom.

KEYWORDS: X-men; Gender; Abjection; School.

$$
* * *
$$

\section{Introdução}

Animações e personagens como super-heróis têm sido alvo de trabalhos que buscam explorar sua aplicabilidade enquanto recurso didático para a educação de crianças, adolescentes e adultos nos mais variados temas.

Segundo Ramalho e Belo (2017), o termo animação pode ser resumido em "animar", "dar vida a" que é basicamente o processo de dar vida e alma a objetos inanimados, e aplica-se ao que diz respeito a filmes de animação. Houve uma inovação nos últimos anos com a apresentação de enredos mais criativos e condizentes com a realidade contemporânea. No entanto, discussões sobre gênero e sexualidade ainda aparecem nessas animações de formas ultrapassadas, conservadoras ou escassas. Isso se deve ao fato de tais temas ainda serem vistos como um assunto delicado, não apenas do ponto de vista da indústria da animação, como também, da parte dos pais dos jovens que são, na maioria das vezes, o público alvo dessas animações. Apesar dessas dificuldades, alguns filmes de animação têm abordado discursos e construções de personagens que possibilitam tocar nas questões relacionadas ao gênero, à sexualidade e à construção de identidades por via de metáforas e alegorias. 
Por alegoria compreendemos um discurso que "[...] faz entender outro ou alude a outro, que fala de uma coisa referindo-se a outra, uma linguagem que oculta outra, uma história que sugere outra" (MOISÉS, 2004, p. 14). A alegoria pode empregar palavras, figuras, pessoas, imagens e animais para compor e fazer compreender o outro a qual se refere. Em outras palavras, ela se torna um instrumento para facilitar a compreensão de uma determinada ideia.

Diante desse quadro, é possível observar que há muitos personagens ícones da cultura pop que podem ser trabalhados como alegorias de questões de gênero e sexualidade. É o caso dos $X$-men.

Os X-men surgiram em uma revista em quadrinhos da editora Marvel em 1960 e após alguns anos ganharam séries animadas na TV e uma franquia de filmes no cinema. Eles são um grupo de heróis muito peculiares: eles nasceram com poderes dos mais variados tipos devido ao chamado gene $\mathrm{X}$. Esses sujeitos são conhecidos como mutantes.

Os mutantes são basicamente uma minoria social. Mais especificamente: uma alegoria das minorias sociais da vida real, portanto, também podem ser usados enquanto um recurso para discutir temas relacionados a elas. Stan Lee, criador da Marvel, diz em uma entrevista que concebeu os $X$-men como uma alegoria daqueles que são discriminados por suas diferenças na vida real. No caso, se trata de grupo de heróis que em razão de suas características únicas sofrem com preconceito e discriminação da sociedade e buscam proteger um mundo que os teme e odeia (CLAREMONT; LEE, 2014).

Segundo a Enciclopédia Marvel:

Todos os dias, nascem mutantes em números cada vez maior - e o pânico e a paranoia da humanidade crescem exponencialmente. Os Mutantes são chamados de aberrações, monstruosidades genéticas. São humilhados, temidos, ofendidos, acusados... de roubar trabalhos humanos, comer alimentos humanos e tomar cônjuges humanos. No entanto, eles continuam emergindo nas cidades, subúrbios, desertos e selvas. Precisam de professores, pessoas que os ajudem a superar a ira e os ensinem a usar suas estranhas habilidades de forma responsável. Sob nuvens de um crescente sentimento antimutante, o professor $\mathrm{x}$ criou um abrigo seguro em sua mansão em Winchester, para treinar jovens a usarem seus dons genéticos únicos para o aprimoramento de todos. Odiados e temidos pela humanidade, esses párias aventureiros continuam a aperfeiçoar seus estranhos poderes enquanto defendem o mundo dos mutantes que tiram vantagens de suas capacidades para subjugar a espécie humana. (BEAZLEY; YOUNGQUIST; BRADY, 2005, p. 162) 
Segundo Braga Jr. (2015), a partir de 1960 a editora Marvel começou a assimilar temas sociais discutidos na opinião pública como elementos para a construção de histórias e personagens em suas histórias em quadrinhos. Essa nova forma de criar histórias ficou conhecida como o "Método Marvel”. Stan Lee, o criador da Marvel, teria visto nesse método uma forma de buscar novas ideias para as suas HQs e de aumentar as vendas. Lee observou que alguns leitores ao lerem tais histórias começavam a discutir sobre elas com outros colegas, o que impulsionava o interesse de novos leitores a comprar as revistas em quadrinhos.

A percepção de leitores e expectadores dos $X$-men sobre os dramas vividos pelos mutantes também foi alvo de alguns estudos. Mangueira (2017), ao analisar o livro No presente de Márcio El-Jaick, discorre sobre como o protagonista dessa obra vê nos $X$ men uma alegoria de suas vivências enquanto alguém que está descobrindo sua sexualidade como um adolescente homossexual. Segundo Mangueira (2017), é evidente que a identificação com esses heróis tem papel significativo no processo de autodescoberta do protagonista como homossexual. Isso denota que Márcio El-Jaick, autor do livro analisado, também vê os $X$-men como alegoria de grupos discriminados em razão de suas diferenças assim como Stan Lee idealizou esses heróis.

Dumont e Ramos (2018), em uma pesquisa com leitores de quadrinhos da Marvel e DC observaram como a leitura das histórias dos heróis dessas editoras desperta em quem lê a percepção de que os enredos têm relação com os seus cotidianos. Em especial, em uma das entrevistas vemos um entrevistado gay que se identificou com uma $X$-men que na história foi discriminada por ser mutante. $\mathrm{O}$ entrevistado identificou semelhanças entre o preconceito contra mutantes e o preconceito contra gays.

Porém, segundo Eisner (1989), no que diz respeito a revistas em quadrinhos é preciso que o autor e o leitor compartilhem de uma comunidade de experiência para que esse entenda a mensagem do artista. Nem sempre, leitores e expectadores compreendem a mensagem na alegoria de determinadas histórias. De acordo com Margonari e Braga Jr. (2015), os jovens consomem quadrinhos com prazer e sem que outros lhe digam para fazê-lo, pois acreditam se tratar de meros produtos de entretenimento. Muitos deles não percebem que esse material muitas vezes taxado como "cultura inútil" é extremamente rico de mensagens culturais que eles em um primeiro momento não percebem que fazem parte de seu cotidiano, se tornando, portanto, um recurso pedagógico a ser explorado por educadores para trabalhar com seus educandos. 
Acreditamos que as animações dos $X$-men, que são derivadas desses quadrinhos, possuem esse mesmo potencial didático. Por isso é necessário que essa alegoria seja tornada explícita para que a mensagem possa ser reconhecida e discutida. Do nosso ponto de vista, os $X$-men são o grupo de super-heróis da Marvel que melhor representam as questões vividas por minorias sociais na vida real, uma vez que suas histórias retratam conflitos de auto aceitação, medo de rejeição, preconceito, discriminação e ao mesmo tempo mostram luta desses para a construção de uma sociedade mais aberta e que aceite as diferenças.

Alguns autores já exploraram essa alegoria dos mutantes para discutir temas relacionados a minorias sociais. Braga $\mathrm{Jr}$ (2015) aponta que a criação dos X-men coincidiu com o discurso "I have a dream" do ativista negro Marthin Luther. Sendo que a primeira HQ desse grupo de heróis foi lançada em 1963, mesmo ano que Martin Luther King fez esse discurso histórico. Campos (2016) discute como as personalidades do Professor $\mathrm{X}$ e Magneto foram inspiradas nas personalidades dos ativistas negros Martin Luther King e Malcon X. Nos anos 60, o debate racial em torno das reivindicações do movimento negro estava em alta e a Marvel viu nesse momento político uma inspiração para novos personagens. No entanto, naquele momento, era complicado tratar temas ligados à questão racial de forma direta nos quadrinhos sem que isso acarretasse a rejeição de um público até então mais conservador em relação a essa temática. A solução foi transpor tais temas sob a forma de alegoria para as HQs, o que demonstrou ter sido uma estratégia bem-sucedida.

Além da discussão racial, outros trabalhos já exploraram a possibilidade de usar a alegoria dos mutantes para temas ligados a outras minorias sociais. Ilea (2009) relaciona a cura mutante do filme $X$-men - O Confronto Final (2006) com a discussão da deficiência física. Essa autora defende que os argumentos pró e contra a cura mutante, assim como os desejos de alguns mutantes de se submeterem ou não à cura, podem ser usados como uma alegoria das discussões sobre deficientes físicas realizarem alterações corporais em seus corpos para colocá-los dentro de uma norma corporal ou não. Já Hopkins (2009) argumenta que a discussão sobre a cura mutante pode se referir a aquilo que a sociedade julga como normal e anormal de forma mais ampla.

Weschenfelder, Fradkin e Yunes (2017) apontam que heróis da Marvel e DC passam por adversidades semelhantes às de crianças e adolescentes em situação de vulnerabilidade, como o bullying, por exemplo. Esses autores defendem a exploração dos heróis como exemplo de metamorfose pessoal em intervenções psicoeducacionais 
para a promoção da resiliência em crianças e adolescentes em situação de vulnerabilidade.

Observa-se que há um interesse de pesquisadores na discussão de como os $X$ men são uma alegoria de grupos minoritários. Esse artigo tem como proposta fazer uma aproximação da alegoria da abjeção dos mutantes com a abjeção da população LGBTQI+3 na instituição escolar. Em especial, nas situações vividas pelos mutantes no episódio 33 da série animada $X$-men: Evolution.

\section{Escola, gênero e abjeto}

O episódio 33 de X-men: Evolution recebeu o título de "Opinião Geral" e nele vemos como se tornam difíceis as relações entre os alunos em uma escola pública de ensino regular após a revelação de que os alunos que moram no Instituto Xavier são mutantes e não humanos.

Nesse episódio, após os X-men resgatarem o professor Xavier e derrotarem o vilão Juggernaut no episódio anterior, os alunos do instituto Xavier tentam voltar à sua rotina na escola de ensino básico de Bayville, mas tem que encarar o crescente sentimento antimutante por parte dos outros alunos humanos e também lidar com diretor Kelly que não os quer mais lá.

Segundo Miskolci (2017), historicamente a escola tem sido um local de normalização a serviço do Estado. É na escola, enquanto espaço de socialização secundária, que os sujeitos se deparam com a sociedade e suas demandas. Não que na família, enquanto espaço de socialização primária, eles já não estivessem inseridos na sociedade, mas é na escola que o sujeito fora do cordão de proteção do núcleo familiar é apresentado às exigências da sociedade além do círculo do parentesco. Exigências e demandas, por vezes imposta de maneira muito violenta, tendo entre uma de suas expressões mais conhecidas o bullying.

Em um primeiro momento recorreremos a Butler (2017) para compreender o conceito de abjeção. Em suas teorizações iniciais sobre o gênero, Butler toma a ideia de abjeto de Julia Kristeva para se referir a todos aqueles que estão fora dos chamados gêneros inteligíveis. Um gênero inteligível, segundo a autora, é aquele que de acordo com normas culturais estabelece uma relação de coerência e continuidade entre sexo, gênero, desejo e prática sexual. Isso pode ser compreendido por meio das seguintes

3 Lésbicas, gays, bissexuais, transgêneros, queer, intersexuais e outras identidades não nomeadas que podem vir a surgir. 
lógicas: pênis - identidade masculina - orientação sexual heterossexual - relações sexuais como "ativo"; vagina - identidade feminina - orientação sexual heterossexual relações sexuais como "passiva".

Segundo Butler (2017), essa relação de continuidade e coerência é instituída e "naturalizada" pela heterossexualidade compulsória que é reiterada por várias instituições como família, mídia, igrejas e, objeto de estudo desse artigo, a escola. Aqueles que não se enquadram nessa relação de continuidade e coerência se tornam gêneros não-inteligíveis, o abjeto. O abjeto é aquilo que é expelido para fora do corpo (fezes, urina, suor etc.) e que ao ser expulso delimita os contornos do sujeito e a distinção interno/externo.

[...] O corpo abjeto é aquilo que não queremos ver em nós mesmos: nossos excrementos e nossos excessos. A ideia de abjeto passa do plano individual ao social e coletivo. Passa-se de um corpo biológico a um corpo social. Os excessos, seja daquilo que causa nojo quanto daquilo que causa prazer, devem ficar de fora do sujeito e da sociedade, devem se tornar um outro (PORCHAT, 2014, p. 307).

Assim, segundo Miskolci (2017), a abjeção se refere ao espaço que a coletividade impõe a todos aqueles que são vistos como uma ameaça ao seu funcionamento, ordem social e política. No campo social, ser abjeto é ser temido e ser alvo de recusa ao ser encarado com repugnância, uma vez que sua existência é tida como uma ameaça à visão e estabilidade do que é a comunidade, ou como radicaliza Butler (2017), a aquilo que é considerado "humano".

A literatura sobre pessoas que vivem experiências em desacordo com as expectativas de gênero inteligível aponta a escola como um espaço de solidão e terror. Segundo Bento (2011), a escola é um espaço de reprodução dos valores hegemônicos. Há uma engenharia social que visa construir corpos "normais" que extrapola os limites da escola, mas que encontra nessa instituição um local ideal para a sua disseminação. A escola demonstra ter claros limites para lidar com as diferenças.

Com base nisso, buscaremos fazer uma aproximação entre as situações vividas pelos mutantes no episódio analisado com as vivências de homossexuais e transexuais da vida real.

Segundo Bento (2011), os relatos de sujeitos que sofreram com a homofobia dentro do ambiente escolar, poucos são acompanhados de falas sobre ações dos educadores para discutir sobre diversidade, diferença, respeito na sala de aula e na escola em geral. 
Bento (2011) também aponta que é alto o número de pessoas que vivem a experiência transexual que desistem e abandonam os estudos. As causas desse abandono são mascaradas pelo conceito de evasão escolar, quando na verdade há um verdadeiro processo de expulsão, onde o ambiente escolar tentar expelir para fora de si esses seres abjetos que o habitam, mas não são aceitos dentro de si. São vistos como poluentes e que podem "contaminar" esse ambiente, e, por isso, devem ser eliminados. Dessa forma, a escola é uma das muitas instituições que tem papel importante na abjeção de homossexuais, bissexuais, transexuais e outros.

A partir do que é apontado por Bento (2011) podemos tecer aproximações entre o que é vivido pelos mutantes no episódio e que é vivido por homossexuais e transexuais na escola.

Antes de iniciarmos a discussão desse trabalho, vale mencionar que Butler esclarece que a forma como concebe o abjeto não se restringe apenas ao sexo e à heteronormatividade, mas a todos aqueles corpos cujas vidas não são consideradas vidas e cuja materialidade são vistas como "não importantes" por não se encaixarem em alguma norma, como deficientes físicos e refugiados por exemplo (PRINS, MEIJER, 2002). Os mutantes são sim considerados abjetos pela forma como são tratados pela sociedade em suas histórias fictícias. Mas, como ressaltamos anteriormente, focaremos na alegoria da abjeção dos mutantes com a abjeção de sujeitos não-heterossexuais na escola.

No decorrer desse artigo buscaremos fazer um estudo descritivo onde, à luz da bibliografia relativa ao tema da abjeção no ambiente escolar, relacionaremos as situações vividas pelos mutantes na escola com as de homossexuais, transexuais e outros que não estão em acordo com a norma heterossexual. De modo que essa alegoria venha a se tornar um material interessante para que educadores possam trabalhar a questão abjeção nas instituições escolares.

\section{"Ninguém quer vocês nessa escola"}

X-men: Evolution, enquanto uma adaptação dos quadrinhos que deram origem aos $X$-men, se propõe a narrar a história de personagens clássicos da franquia como adolescentes que estudam em uma escola pública com alunos humanos, enquanto em segredo aprendem a usar e controlar seus poderes no Instituto Xavier para Jovens Superdotados sob a tutela do Professor Xavier, o telepata mais poderoso do mundo. São 
vários os alunos que estudam no Instituto Xavier, mas os personagens principais, incluindo alguns professores, são Ciclope, Jean Grey, Lince Negra, Fera, Noturno, Spyke, Wolverine, Tempestade e Vampira.

Nos primeiros episódios desse desenho animado a condição dos alunos mutantes é mantida em segredo da comunidade escolar. Mas após alguns eventos envolvendo o vilão Magneto e a irmandade de mutantes, os alunos mutantes acabam sendo descobertos e o fato de serem sujeitos dotados de poderes se torna de conhecimento público. No episódio de X-men: Evolution analisado vemos as consequências dessa descoberta no cotidiano escolar dos personagens.

Logo na cena inicial, durante a noite, vemos um grupo de rapazes encapuzados indo para o Instituto Xavier, local onde os personagens mutantes dormem e treinam seus poderes, fazer pichações com desenhos e palavras injuriosas contra eles. Ao serem confrontados pelos personagens Noturno e Lince Negra, eles acabam fugindo, mas antes de saírem da propriedade do Instituto dirigem ofensas aos mutantes os chamando de aberrações. Isso é apenas o prelúdio do que aguarda os alunos mutantes no mesmo dia de aula. Ao irem para a escola pública onde estão matriculados, os mutantes são recebidos com olhares hostis e ofensas como "aberrações" por parte dos alunos humanos. Chegam a ouvir que aquela escola não é lugar para mutantes.

A situação dos mutantes na escola ainda leva alguns desses a desistir dos estudos, como é o caso do grupo rival dos $X$-men, a Irmandade de mutantes. Outros alunos que moram no Instituto Xavier são tirados de lá e da comunidade escolar por seus pais devido ao medo de rejeição e violência que seus filhos sofreriam. Como já dito anteriormente, assim como ocorre como homossexuais, bissexuais e transexuais, o processo de expulsão é muitas vezes mascarado pelo conceito de evasão.

Tal como os mutantes, sujeitos apontados como "estranhos", em especial, homossexuais e transexuais são alvos de chacotas e agressões verbais como xingamentos. Segundo Miskolci (2014), o preconceito contra sujeitos nãoheterossexuais é algo ainda muito aceito na nossa sociedade, e muitos não têm receio de manifestar sua rejeição a eles. No caso dos mutantes, assim como com homossexuais e transexuais, vemos de forma muito explícita alunos manifestando palavras e atos violentos contra eles sem qualquer inibição. Uma dessas manifestações de rejeição é o bullying.

O bullying é, segundo Miskolci (2017), o caráter violento da socialização escolar. Embora alguns acreditem se tratar de um fenômeno novo, o bullying sempre foi 
parte do processo educacional. Não se trata de uma invenção recente, mas sim da nomeação de um fenômeno que existe há muito tempo na instituição escolar, bem como, de uma mudança na forma como ele é visto. Hoje as pessoas se sensibilizam mais com relação às formas de violência que o bullying expressa.

O bullying, segundo Ristum (2010), pode ocorrer de forma direta ou indireta. A forma direta se caracteriza por agressões físicas e verbais, enquanto a indireta se manifesta por comentários e fofocas que podem ser de cunho racista, homofóbico, sexista e outros, além da exclusão social. Ainda, segundo a autora, o bullying se caracteriza ainda por 3 critérios:

1. comportamento agressivo e intencionalmente nocivo; 2 . comportamento repetitivo (perseguição repetida); 3. comportamento que se estabelece em uma relação interpessoal assimétrica, caracterizada por uma dominação (RISTUM, 2010, p. 96).

Os mutantes no decorrer do episódio passam a ser vítimas de bullying direto e indireto. De forma indireta porque são alvos de injúria e isolamento. O bullying indireto é percebido quando amigas de Jean Grey passam a ignorá-la depois de descobrirem que ela é mutante, assim como também tentam a isolar na aula de educação física.

O bullying direto passa a acontecer diante das agressões físicas por parte de alguns alunos. O personagem Ciclope, por exemplo, é agredido por um grupo de rapazes que tentam se aproveitar do fato de ele não poder usar seus poderes para se defender. Em outra cena um desses rapazes reaparece para confrontar Ciclope e tentar com isso garantir sua expulsão da escola.

Indo além desse episódio em questão, vemos situações de bullying, especialmente o indireto, se repetindo. Assim, podemos classificar essas situações como bullying por seu aspecto repetitivo, tal como postula Ristum (2010).

A cena de bullying envolve três atores: o agressor, a vítima e o espectador (RISTUM, 2010). No caso do espectador, esse assiste a cena de bullying e nada faz para impedir o agressor, seja por apoiá-lo ou por ter medo de se tornar alvo dele. É o que ocorre com o personagem Noturno que assiste o personagem Ciclope ser hostilizado por outros alunos e nada faz para ajudar o amigo devido ao medo de também se tornar um alvo.

Os dirigentes da escola também passam a empreender uma cruzada para que mutantes saiam da instituição escolar que comandam. $O$ diretor Kelly nada faz em relação a um grupo de alunos humanos que estava hostilizando o personagem Ciclope 
que é mutante, assim como também nada faz diante dos casos de insultos e ridicularização dirigidos aos demais alunos mutantes.

Tomaremos emprestada a teorização que Dinis (2011) faz do conceito "amolador de faca" para o contexto escolar para analisar as atitudes do diretor Kelly referentes à omissão diante da hostilidade dos alunos frente aos mutantes assim como pela incitação do sentimento antimutante como as descritas no parágrafo anterior e a seguir no decorrer do texto.

Segundo Dinis (2011), o conceito "amolador de faca" foi criado pelo psicólogo Luiz Antônio Baptista “[...] para denunciar a cumplicidade social com a violência expressa, às vezes, no discurso da mídia, no discurso religioso e no discurso de saberes com a Psicologia e a Psiquiatria, mas que podemos aplicar também ao discurso educacional" (DINIS, 2011, p.44). Essa metáfora se refere a aqueles que por meio de seus discursos, falas aparentemente destituídas de crueldade e silêncios fortalecem a "faca" e enfraquecem as vítimas dessa. Trata-se daqueles que não são responsáveis diretos por atos de violência, mas que com seus atos, deliberados ou não, preparam o palco para a emergência desses. Não empunham a "faca" no ato de violência, mas "amolam o seu fio". Educadores também podem ser amoladores de faca para a abjeção de sujeitos não heterossexuais. Sendo omissos diante dos casos de bullying na escola os educadores agem como amoladores de faca.

Pensando essa situação como alegoria das situações vividas por alunos nãoheterossexuais, uma das formas de violência mais sutis e talvez a mais cruel de invisibilizar a sexualidade, segundo Miskolci (2014), é o silêncio de educadores em relação à emergência dessa quando é diferente daquela imposta pela heteronormatividade. Longe de ser uma atitude neutra, esse silêncio é uma tentativa de eliminar essa sexualidade abjeta. O silêncio torna esses educadores cumplices da ridicularização e insultos públicos que atingem a população LGBTQI+.

Na cena da aula de educação física, vemos a personagem Jean Grey em um jogo de basquete. Percebemos que ela está sendo ignorada pelas outras jogadoras humanas, mas ela ainda tenta continuar no jogo e consegue fazer uma cesta. Mas logo é acusada de usar seus poderes para fazer o ponto. Jean tenta se defender dizendo que não usou seus poderes, mas a treinadora a manda para o banco sem maiores explicações, dando razão implicitamente para as outras jogadoras. Mais uma vez, outra educadora, de forma breve, age como amoladora de faca ao silenciar sobre uma situação de injustiça em sua aula. 
Na sequência da cena na aula de educação física, Jean vê o diretor Kelly retirando os troféus que a escola ganhou pelo bom desempenho dos alunos nos campeonatos esportivos. Ele diz que foi aberta uma sindicância para apurar se tais prêmios eram de fato merecidos devido à suspeita de que alunos mutantes possam ter usado seus poderes para se sobressair no esporte. Jean protesta, mas é desacreditada pelo diretor. Essa cena do episódio ainda nos faz lembrar da discussão acerca de mulheres transexuais em categorias femininas no esporte. Um exemplo um pouco recente é o da jogadora transexual Tiffany no vôlei. Seu rendimento nos jogos tem sido muito questionado devido ao fato de já ter tido altas taxas de testosterona no corpo antes da transição de gênero. Tal aspecto faria com que ela tivesse uma vantagem injusta no seu rendimento como jogadora. Porém, na maioria das vezes pouco se discutiu se seu rendimento estaria ligado ao tipo de treinamento que ela recebeu quando atuou nas ligas masculinas antes da transição. A discussão recaiu sobre uma suposta vantagem biológica e ignorou como a separação de homens e mulheres no esporte contribui para acentuar a diferença entre eles.

Há também uma incitação para os atos de rejeição aos mutantes. A permanência dos mutantes na escola até a realização do conselho escolar que decidiria se iriam ser expulsos ou não, foi condicionada à não utilização de seus poderes dentro da instituição de ensino. Então, o diretor Kelly passa instigar um aluno humano a praticar atos de bullying contra os alunos mutantes na escola com o claro intuito de que isso culmine na expulsão desses se vierem a utilizar seus poderes para se defender. Em outra cena vemos esse mesmo diretor incitar um grupo de mutantes rebeldes chamado a Irmandade de Mutantes a confrontar os $X$-men durante a realização do conselho para que usassem seus poderes e assim fossem expulsos.

Essas situações são uma das muitas nuances de como educadores são amoladores de faca para inúmeras situações de violência física e simbólica contra alunos em desacordo com as normas de gênero acentuando ainda mais sua abjeção.

A abjeção na escola ainda força que alunos em desacordo com as normas de gênero escondam suas orientações sexuais, no caso, que fiquem dentro do "armário". O “armário", segundo Prado e Machado (2012) é o termo popularmente usado para se referir a aqueles que escondem suas orientações sexuais, que os leva a viver uma vida dupla.

O personagem Noturno, cuja verdadeira aparência é parecida com um demônio de pelo azul, usa um projetor holográfico que o faz adquirir uma aparência considerada 
humana. No início do episódio, ao se dar conta que os alunos humanos não sabiam de sua verdadeira forma azul e que, portanto, ainda acreditavam que ele era humano comum, Noturno passa então a tentar esconder a todo custo que é mutante.

Essa situação do personagem Noturno pode ser comparada com a situação de sujeitos não-heterossexuais no armário. O armário é um importante dispositivo regulador da vida social, e ele não diz respeito somente a aqueles que vivem suas vidas afetivas e sexuais em segredo, mas também diz respeito a aqueles, no caso sujeitos heterossexuais, que têm o privilégio de vivê-las abertamente. O temor de ser alvo da abjeção, com fontes reais em situações de violência verbal e física, faz com que sujeitos destoantes das normas de gênero busquem viver suas vidas em segredo (MISKOLCI, 2007).

Segundo Louro (2018), a escola é certamente um dos locais mais difíceis para que homossexuais, bissexuais e transexuais assumam suas sexualidades sem culpa ou vergonha. Essa situação pode ser comparada com a vivida pelo personagem Noturno que começa a andar separado de seus amigos mutantes para que ninguém desconfie que ele é mutante. Ele em um determinado momento chega a dizer que parecer ser normal é a melhor coisa que lhe ocorreu. Mas Scott Summers/Ciclope, seu amigo do Instituto Xavier, logo lhe alerta que cedo ou tarde acabarão descobrindo de sua condição como mutante, e ele de forma cabisbaixa concorda. Mas no decorrer do episódio ainda tenta se passar por um humano.

No final do episódio, Noturno acaba revelando seus poderes de teleporte, porém, ainda diz não ser capaz de assumir sua verdadeira aparência azul e demoníaca. Isso nos permite fazer mais uma aproximação com a situação vivida por sujeitos nãoheterossexuais na escola, onde aqueles que são os alvos preferenciais da violência são justamente os assumidos e aqueles que estão em desacordo com as normas de gênero de forma mais visível como meninos afeminados, meninas masculinizadas e transgêneros. Homossexuais que se mostram próximos da performance de gênero esperada de meninos e meninas, assim como os enrustidos são os alvos menos atacados (MISKOLCI, 2017; LOURO, 2018).

A escola enquanto um espaço de normalização, incentiva esse jogo de segredo/revelação e público/privado em relação à sexualidade. Segundo Louro (2018, p. 38), na “[...] escola, seja pela afirmação ou pelo silenciamento, nos espaços reconhecidos e públicos ou nos cantos escondidos e privados, é exercida uma pedagogia da sexualidade, legitimando determinadas identidades e práticas sexuais, reprimindo e 
marginalizando outras". No caso, a homossexualidade, transexualidade e outras manifestações dissidentes das normas de gênero têm sido especialmente relegadas ao privado enquanto a heterossexualidade se mantém pública, de forma a legitimar essa e marginalizar as demais sexualidades.

No início do episódio isso fica evidente quando a escola estabelece que para que os mutantes permaneçam no ambiente escolar, eles devem não usar seus poderes de forma alguma, caso contrário seriam expulsos. Nota-se aqui um esforço da escola em garantir o espaço público para aqueles que são considerados humanos e relegar os que não são humanos ao privado por meio do ocultamento de seus poderes, o que nos permite fazer outra aproximação com a escola enquanto um espaço de normalização no que diz respeito à população LGBTQI+.

Durante a reunião do conselho da escola, a irmandade de mutantes junto a um aluno humano, após serem instigados pelo diretor Kelly, atacam o salão onde ocorre a reunião. Os $X$-men mostram nesse momento autocontrole ao não usar seus poderes para enfrentar a irmandade. Mas no decorrer do confronto acabaram utilizando seus poderes para salvar os humanos que estavam em perigo. O embate termina e os $X$-men ficam então, receosos como seu futuro na escola.

\section{"Mesmo em face do preconceito e da discriminação, os $x$-men vão sobreviver"}

Ao final do episódio, o conselho escolar decide pela permanência dos mutantes na escola. Mas os mutantes estão receosos com o futuro mesmo assim. O professor Xavier tenta animá-los dizendo que a chance que eles têm nessa escola é uma honra e uma oportunidade de plantar a semente da mudança para que os próximos mutantes a pisarem lá encontrem um ambiente mais acolhedor.

Como já mencionamos antes, chama a atenção o fato de que na animação de $X$ men: Evolution os mutantes do Instituto Xavier estudarem em uma escola pública com humanos ao invés de estudarem em uma escola específica somente para mutantes como nos quadrinhos. A mensagem que isso parece passar é de como conviver com as diferenças é algo enriquecedor. Isso fica evidente no confronto dos $X$-men com a irmandade de mutantes, quando os alunos do Instituto Xavier utilizam seus poderes para salvar os humanos que estavam em perigo no confronto. No caso, as mesmas diferenças que eram motivo de exclusão se mostraram cruciais para que o confronto não fizesse vítimas fatais. 
Miskolci (2017), à luz da teoria queer, fala sobre os desafios de uma educação que não seja normalizadora, ou, em suas palavras, em um aprendizado pelas diferenças. É preciso mais do que assimilar as diferenças à cultura. É preciso questionar a própria abjeção.

Butler (2017) entende que é a partir do abjeto que podemos entender como o mundo corriqueiro dos significados sexuais é produzido e naturalizado, e ao mesmo tempo, como poderia ser pensado de outra forma. Nas palavras de Miskolci (2017, p. 70), “[...] ao invés de ensinar e reproduzir a experiência da abjeção, o processo de aprendizado pode ser de ressignificação do estranho, do anormal como veículo de mudança social e abertura para o futuro".

\title{
Conclusão
}

Buscamos tecer aproximações das vivências dos mutantes no episódio 33 da animação X-men: Evolution com as vivencias da população LGBTQI+ na escola à luz da bibliografia acerca do tema da abjeção na escola.

Stan Lee em um vídeo gravado em 2017 como resposta a alguns fãs que protestavam contra a crescente inclusão de personagens diversos nas histórias da Marvel, ele afirma que as histórias da editora sempre foram um espaço para todos independentemente de suas diferenças. O vídeo foi postado no canal oficial da Marvel, no Youtube, e nele Stan Lee diz:

\begin{abstract}
A Marvel foi e sempre será um reflexo do nosso mundo. Ela pode mudar e evoluir, mas algo que nunca mudará é como contamos nossas histórias de heroísmo. Essas histórias têm espaço para todos, independentemente de seu gênero, cor de pele e religião. As únicas coisas para que não temos espaço são o ódio, a intolerância e o preconceito. Aquele homem ao seu lado é seu irmão. Aquela mulher, sua irmã. E aquela criança passando, quem sabe, pode até ter a força proporcional de uma aranha. Somos parte de uma só grande família, a família humana, e todos nos reunimos nas obras da Marvel (LEE, 2017).
\end{abstract}

Acreditamos que a situação escolar vivida pelos mutantes na animação $X$-men: Evolution possa ser usada como um recurso para educadores trabalharem a questão das diferenças com os educandos em sala de aula. E especial, buscamos destacar a potencialidade para trabalhar questões de gênero e abjeção a partir de heróis como os $X$ men.

Os mutantes, também abjetos, nos oferecem uma oportunidade, dentro do contexto de X-men: Evolution, de refletir sobre a instituição escolar e seu papel na 
construção do que significa ser humano. Entendemos também que causar essa reflexão era um dos desejos de Stan Lee, criador da Marvel e dos X-men.

\section{Referências}

BEAZLEY, Mark; YOUNGQUIST, Jeff; BRADY, Matt. Enciclopédia Marvel. São Paulo: Panini Comics, 2005.

BENTO, Berenice. Na escola se aprende que a diferença faz a diferença. Rev. Estud. Fem., Florianópolis , v. 19, n. 2, Ago. 2011.

BRAGA JR, Amaro Xavier. Por uma sociologia da imagem desenhada: reprodução, estereótipo e actância nos quadrinhos de super-heróis da Marvel Comics. 2015. Tese (Doutorado em Sociologia) - Universidade Federal de Pernambuco, Recife, 2015b.

BUTLER, Judith. Problemas de gênero. Feminismo e subversão da identidade. $14^{\mathrm{a}} \mathrm{ed}$. Rio de Janeiro, Civilização Brasileira, 2017.

CAMPOS, Jeferson. X-men e a alegoria da luta dos direitos humanos dos negros e a "heroicidade" de Martin Luther King e Malcon X. Revista Eletrônica da FEATI, v.1, n.12, p.190-194. Jan-jul, 2016.

CLAREMONT, Chris; LEE, Stan. Chris Claremont e Stan Lee falam sobre os X-Men. 2014. (20m23s). Disponível em: https://www.youtube.com/watch?v=yhxP5eeE_nA

DINIS, Nilson Fernandes. Homofobia e educação: quando a omissão também é signo de violência. Educ. rev., Curitiba , n. 39, p. 39-50, Abr. 2011.

DUMONT, Lígia Maria Moreira; RAMOS, Rubem Borges Teixeira. A leitura de histórias em quadrinhos da Marvel e da DC Comics e a etnometodologia: relevância e desdobramentos. Perspect. ciênc. inf., Belo Horizonte, v. 23, n. 3, p. 188-205, Set. 2018.

EISNER, Will. Quadrinhos e arte seqüencial. São Paulo: Martins Fontes; 1989.

HOPKINS, Patrick D. A Sedução do normal: Quem não quer ser mutante? In: Irwin, W. (Org.). X-men e a filosofia: visão surpreendente e argumento fabuloso no X-universo mutante. (Trad. Marcos Malvezzi). São Paulo: Madras, 2009.

ILEA, Ramona. A cura mutante ou mudança social: Debatendo a deficiência. In: Irwin, W. (Org.). X-men e a filosofia: visão surpreendente e argumento fabuloso no Xuniverso mutante. (Trad. Marcos Malvezzi). São Paulo: Madras, 2009.

LEE, Stan. A Message From Stan Lee. 2017. (1m17s). Disponível em: https://www.youtube.com/watch?v=sjobevGAYHQ\&t=10s. Acesso em: 13 de mar 2020.

LOURO, Guacira Lopes. O corpo educado. Pedagogias da Sexualidade. 4a. ed. Belo Horizonte: Autêntica Editora, 2018. 
MANGUEIRA, José Villian. A utilização dos X-men como identidade gay no livro No Presente, de Márcio El-Jaick. Darandina Revisteletrônica, v. 10, p. 1-13, 2017.

MARGONARI, Denise Maria; BRAGA JR, Amaro Xavier. O humor das tiras em quadrinhos na educação para a diversidade sexual. Revista Ibero-americana de Estudos em Educação, v. 10, p. 1603-1621, 2015.

MISKOLCI, Richard. Comentário. Cad. Pagu, Campinas , n. 28, p. 55-63, Junho, 2007 .

MISKOLCI, Richard. Teoria Queer: um aprendizado pelas diferenças. 3. ed. Belo Horizonte: Autêntica, 2017.

MISKOLCI, Richard. Marcas da diferença no ensino escolar. 1. reim. São Carlos: EdUFSCar, 2014. v. 1.

MOISÉS, Massaud. Dicionário de termos literários. 12. Ed. São Paulo: Cultrix, 2004.

PORCHAT, Patricia. Gênero é um outro. In: MINELLA, Luzinete Simões; ASSIS, Gláucia de Oliveira; FUNCK, Suzana Bornéo. (Org.). Políticas e fronteiras: desafios feministas. 1ed. Tubarão: Editora Copiart, 2014, v. 2, p. 295-308.

PRADO, Marco Aurélio Máximo; MACHADO, Frederico Viana. Preconceito contra homossexualidades: a hierarquia da invisibilidade. 2. ed. São Paulo: Cortez, 2012.

PRINS, Baukje.; MEIJER, Irene Costera. Como os corpos se tornam matéria: entrevista com Judith Butler. Rev. Estud. Fem., Florianópolis, v. 10, n. 1, p. 155-167, Jan. 2002.

RAMALHO, Felipe de Castro; BELO, Fábio. Identidade de gênero não-inteligível e o cinema de animação: o caso de Lenny, de O Espanta Tubarões. Bagoas - Estudos gays: gênero e sexualidades, v. 11, p. 268/03-290, 2017.

RISTUM, Marilena. Bullying escolar. In: ASSIS, Simone Gonçalves;

CONSTANTINO, Patrícia; AVANCI, Joviana Quintes. (Org.). Impactos da violência na escola - refletindo com os professores sobre o enfrentamento da violência. Rio de Janeiro: FIOCRUZ-MEC, 2010, p. 95-119.

WESCHENFELDER, Gelson Vanderlei; FRADKIN, Chris; YUNES, Maria Angela Mattar. Super-heróis como recursos para promoção de resiliência em crianças e adolescentes. Psic.: Teor. e Pesq., Brasília, v. 33, e33425, 201 